\title{
Erratum to: Text Detection in Low Resolution Scene Images Using Convolutional Neural Network
}

\author{
Anhar Risnumawan $^{1(\bowtie)}$, Indra Adji Sulistijono ${ }^{2}$, and Jemal Abawajy ${ }^{3}$ \\ ${ }^{1}$ Mechatronics Engineering Division, Politeknik Elektronika Negeri \\ Surabaya (PENS), Kampus PENS, Surabaya, Indonesia \\ ${ }^{2}$ Graduate School of Engineering Technology, \\ Politeknik Elektronika Negeri Surabaya (PENS), \\ Kampus PENS, Surabaya, Indonesia \\ \{anhar, indra\}@pens.ac.id \\ ${ }^{3}$ School of Information Technology, Deakin University, Geelong, Australia \\ jemal.abawajy@deakin.edu.au
}

\section{Erratum to: \\ Chapter "Text Detection in Low Resolution Scene Images \\ Using Convolutional Neural Network" in:}

T. Herawan et al. (eds.), Recent Advances on Soft Computing

and Data Mining, Advances in Intelligent Systems and Computing, DOI 10.1007/978-3-319-51281-5_37

The original version of the chapter "Text Detection in Low Resolution Scene Images Using Convolutional Neural Network" was published with the co-author name "Younes Saadi" which has to be deleted. The erratum chapter and the book have been updated with the changes.

The updated original online version for this chapter can be found at DOI: $10.1007 / 978-3-319-51281-5 \_37$ 